\title{
Audit of surgical services in a teaching hospital in Addis Ababa, Ethiopia
}

\author{
Hailu Wondimu Gebresellassie* (10) and Girmaye Tamerat
}

\begin{abstract}
Objective: The aim of the study is descriptively analyze services in terms of surgical care, performance and outcome in department of surgery of ZMH which is a university affiliated general hospital in Addis Ababa, Ethiopia. Data on mode of admission, procedures done and outcome were collected from a monthly audit report, patients file. Information on the number of operating days missed and patients cancelled after being scheduled for surgery were collected from OR logo book.

Result: Emergency operations constitute $57.4 \%$ of all operations. Appendectomy is the commonest emergency operation accounting for $41.5 \%$. Thyroid and gallbladder surgeries were the most common elective operations accounting for $23.5 \%$ and $22 \%$ respectively. There were 26 and 2 deaths from the emergency and elective operations making the postoperative mortality rate of $2.8 \%$ and $0.02 \%$ respectively. The average hospital stay of a patient is 3.74 days. 23 of 211 (14.7\%) operation dates were missed for various reasons. 81 of 693 (11.7\%) elective operations were not done the first time they were scheduled. In conclusion this study showed emergency surgery out number elective surgeries, unacceptably high number of operation days are missed and scheduled surgeries are cancelled.
\end{abstract}

Keywords: Audit, Zewditu, Emergency, Elective, Mortality, Operation

\section{Introduction}

Audit in a clinical setting is the collection of data for the purpose of setting professional standards, assessing clinical performances and modifying the clinical practice [1], unlike its usual association with accounting which implies the numerical review by an outside investigator for the prevention of fraud.

In recent years studies had shown the importance of surgery in human health and welfare. Among the $51 \mathrm{mil}-$ lion people who died in 2012, 17 million suffered from a disease that needed surgical service [2].

A recent study on the global burden of postoperative death showed that postoperative deaths account for $7.7 \%$ of all deaths globally and half of these occur in LMICs [3].

Emergency surgery represents over $50 \%$ of general surgical practice in UK. This rises in some hospitals, which provide regional Accident and Emergency services, to nearly $70 \%$, and acute abdominal pain represents approximately half of all emergency surgical admissions [4]. Non

*Correspondence: hailuwgs@gmail.com; hailu.wondimu@aau.edu.et CHS, SOM, AAU, Addis Ababa, Ethiopia traumatic acute abdomen represented $54 \%$ of general surgical admissions in Saudi Arabia [5].

In Ethiopia, a structured program for the clinical audit is not available. It is not a regular practice to conduct surgical audit routinely therefore proper clinical data is not available which can be reviewed and analyzed in terms of morbidity, mortality and other clinical outcomes in order to improve the overall clinical practice.

In this study due the lack of clinical data on surgical audit especially surgical emergency audit, where no comparative figures were available from different institutions, we had no option than to rely on the limited data available elsewhere for comparison.

\section{Main text \\ Materials and methods}

ZMH is university affiliated hospital in the center of city Addis Ababa, Ethiopia with over 120 beds (42 adult and 6 pediatric surgical beds). It has four the four major departments (internal medicine, Obstetrics/gynecology, Pediatrics). 
Data on diagnosis, mode of admission, procedures done (if any) and outcome of patients seen and managed in the department of surgery from June 1, 2016 to May 30, 2017 were retrieved and descriptively analyzed.

The source of the data were patients file, outpatient registration book, inpatient registration book, operation theatre registration books and the monthly audit report of department.

\section{Study design}

This is a retrospective descriptive analysis of surgical services and care at department of surgery. Ethical approval and clearance were gained from AAU-MF IRB office.

\section{Result}

4629 emergency and 4892 new non-emergency patients were seen in department i.e. on the average 12.7 patients per day. 2311 of 4629 (49.9\%) were patients with minor conditions which does not need admission or observation (Tables 1,2). There were 1640 admissions to surgical ward, $866(52.8 \%)$ of which were emergencies. 144 of $1640(8.8 \%)$ admissions were managed conservatively (or surgery deferred for various reasons). There were 240 emergency consultation almost all from department of pediatrics.

There were 866 emergency and 774 elective admissions during the same period. 934 emergency and 693 elective major surgeries were performed. Emergency operations constitute $57.4 \%$ of all operations. Appendectomy is the commonest emergency operation accounting for $41.5 \%$

Table 1 Emergency and elective surgeries department of surgery, Zewditu Memorial Hospital a Teaching Hospitals Experience in Addis Ababa, Ethiopia

\begin{tabular}{|c|c|c|c|c|c|}
\hline Procedure or diagnosis & Frequency & Percentage & Elective procedures & Frequency & Percentage \\
\hline Appendectomy & 388 & 41.5 & Thyroid surgeries & 163 & 23.5 \\
\hline Generalized peritonitis 2 nd to appendicitis & 48 & 5.1 & Cholecystectomy & 152 & 21.9 \\
\hline $\mathrm{LBO}$ & 16 & 1.7 & Prostatectomy & 88 & 12.7 \\
\hline SBO & 24 & 2.6 & Hernia repair & 75 & 10.8 \\
\hline Perforated PUD & 26 & 2.9 & Perianal procedures & 53 & 7.6 \\
\hline Blunt abdominal trauma & 16 & 1.7 & mastectomies & 34 & 4.9 \\
\hline Penetrating abdominal trauma & 18 & 1.9 & Colostomy closure & 19 & 2.7 \\
\hline Re-laparotomy & 16 & 1.7 & CBD exploration & 8 & 1.2 \\
\hline Various abscess drainage & 127 & 13.6 & Vagotomy + GastroJejenostomy & 9 & 1.3 \\
\hline Debridement & 18 & 1.9 & Orchidopexy & 13 & 1.9 \\
\hline Chest tube insertion & 50 & 5.3 & REEA for redundant sigmoid & 29 & 4.2 \\
\hline Others & 187 & 20 & Others & 50 & 7.2 \\
\hline Total & 934 & 100 & Total & 693 & 100 \\
\hline
\end{tabular}

Table 2 service, care, and outcome department of surgery, Zewditu Memorial Hospital a Teaching Hospitals Experience in Addis Ababa, Ethiopia

\begin{tabular}{|c|c|c|c|}
\hline Operation theatre & Operations & Operation theatre activity & Number (\%) \\
\hline \multirow[t]{7}{*}{ OR activity } & Emergency operations & Emergency operations done & 934 (57.4\% of operations) \\
\hline & Elective operations & Scheduled & 774 \\
\hline & & Operated & $693(89.5 \%$ of scheduled) \\
\hline & & Cancelled & 81 (10.5\% of scheduled) \\
\hline & & OR days missed & 23 (10.9\% of operation days) \\
\hline & & Total OR days & 211 \\
\hline & Total number of patients operated & Emergency and elective & $1627(100 \%)$ \\
\hline \multirow[t]{3}{*}{ Surgical referral clinic } & Type of patients & Number of new patients seen in surgical referral clinic & $\begin{array}{l}4892 \text { ( } 45.8 \% \text { of patients } \\
\text { seen in referral clinic) }\end{array}$ \\
\hline & & $\begin{array}{l}\text { Number of Repeat/follow-up patients seen in surgical referral } \\
\text { clinic }\end{array}$ & $5802(54.3 \%)$ \\
\hline & & Number of patients seen in surgical referral clinic & $10,692(100 \%)$ \\
\hline
\end{tabular}


(Table 1). Thyroid and gallbladder surgeries were the most common elective operations accounting for $23.5 \%$ and $22 \%$ respectively (Tables 1,2 ).

There were 26 deaths following emergency surgeries and 2 deaths following elective operations making the postoperative mortality rate of $2.8 \%$ and $0.02 \%$ respectively (Table 3 ). There were no intraoperative death. The average hospital stay of a patient is 3.74 days. 23 of $211(14.7 \%)$ operation dates were canceled for various reasons. 81 of $774(11.7 \%)$ scheduled elective operations were not done the first time they were scheduled (Table 3).

\section{Discussion}

This study showed that most of the patients (49.9\%) presenting to surgical emergency departments like soft tissue injuries etc., do not deserve admission. This has also been the observation in Nigeria and Lahore, India, where $66.5 \%$ do not deserve admissions $[6,7]$. Trauma related major neurosurgical (often head injuries) and orthopedic (such as long bone fracture) cases constitute 11.4\%. The finding is almost similar to a tertiary hospital in Delhi where major orthopedic cases alone constitute 11.64\% [8].

In low and middle income countries (LMICs), studies has showed that at least 60 percent of the surgical operations are performed for emergency patients [9]. Our study also showed $61 \%$ of all major operations performed were for emergency conditions. These fact suggests surgical emergencies may compromise day to day activities of operation theatres and calls for establishment of dedicated operation theatres and staff in emergency department.

The most common emergency surgery is simple or complicated appendicitis, accounting for $46.6 \%, 436$ of 934 emergency procedures. A study done in this hospital from 1996 to 1998 showed that acute appendicitis accounts for $46.7 \%$ of admissions for acute abdomen [10]. These is in accordance with the study on pattern of surgical admissions to Tikur Anbessa where appendicitis was found to be the most common cause of acute abdomen and accounts for $37.4 \%$ of GI emergencies [11]. This has been confirmed by multicenter study involving high, middle and low income countries by global surgery collaborative group on mortality of emergency abdominal surgery in high-, middle and low-income countries [12].

An Observational Study of the Etiology, clinical presentation and outcomes associated with peritonitis in Lilongwe, Malawi also showed appendicitis to be the most common cause of peritonitis (22\%) followed by gangrenous bowel obstruction and perforated peptic ulcer disease [13].This study and other studies in Ethiopia has showed perforated peptic ulcer disease to be 2nd most common cause of peritonitis and acute abdomen [14].

A study in Tikur Anbessa hospital has showed that that gallstone disease and thyroid surgeries are the most common indication for elective admission followed by $\mathrm{BPH}$ which is also the same finding in this study [11].

Surgical site infection including postoperative intraabdominal collection is the most commonly encountered cause of morbidity, and mortality in this study, as in Rwanda, Kigali University Teaching Hospital [15]. SSI were found $12.3 \%$ patients in a study on SSI following gastrointestinal surgery across countries with different income level [16].

Septicemia, septic shock and multiple organ failure is what causes death in most postoperative surgical patients as seen in this study [10]. Mortality rate following emergency surgery is $2.8 \%$ (26 out of 934 ) while it is $0.29 \%$ following elective surgery and overall mortality rate 31 out of 1640 admissions $(1.9 \%)$ in these study is much lower than reported in most literatures in Africa [6, 14, 17]. Perioperative mortality is considered a measure of quality of surgical care by WHO and a case study found that

Table 3 Morbidity, mortality, average hospital stay department of surgery, Zewditu Memorial Hospital a Teaching Hospitals Experience in Addis Ababa, Ethiopia

\begin{tabular}{|c|c|c|c|c|c|c|}
\hline Morbidity and mortality & Number per patients & $\%$ & Major post op cx & Number (\%) & Cause of death & No [\%] \\
\hline $\begin{array}{l}\text { Major morbidity (Grade 3-5 } \\
\text { clavien-dindo complications) }\end{array}$ & 56 of 1627 & 3.4 & Deep surgical wound infection & $20(35.7)$ & Intractable septic shock & $17(65.4)$ \\
\hline Non-operative death & 3 of 1640 admissions & 0.1 & Postoperative abscess collection & $18(32.1)$ & Hypovolemic shock & $2(7.7)$ \\
\hline Intra-operative death & 0 of 1627 & 0 & & & & \\
\hline $\begin{array}{l}\text { Post-operative death after emer- } \\
\text { gency surgery }\end{array}$ & 26 of 934 operations & 2.8 & HAP & $8(14.3)$ & PTE & $1(3.9)$ \\
\hline $\begin{array}{l}\text { Post-operative death after elective } \\
\text { surgery }\end{array}$ & 2 of 693 operations & 0.29 & Anastomotic leaks & $7(11.9)$ & HAP & $3(11.5)$ \\
\hline \multirow[t]{2}{*}{ Average hospital stay } & 3.74 days & & Hypo-calcemic tetany & $2(2.4)$ & Cardiac arrest & $3(11.5)$ \\
\hline & & & Total & $56(100)$ & Total & $26(100)$ \\
\hline
\end{tabular}


Perioperative mortality in Madagascar is between 2.5 and $3.3 \%$ while in Uganda it is $2.4 \%$ [18].

A Lancet report on global burden of postoperative death showed that 4.2 million people die within 30 days of surgery globally each year and half of this occurs in LMICs [3].

Our finding on overall mortality and mortality following emergency surgery are lower than that reported by a prospective multicenter study by globalsurg collaborative study of $1.9 \%$ and $6.8 \%$ respectively [3].

Cancellation of elective surgical operations is recognized as a major cause of emotional trauma to patients as well as their families. There is unacceptably high rate of cancellation of elective operations i.e. 10.5\% although there are reports of higher rate in Africa as in a University Teaching Hospital in the Lake Zone, Tanzania [19]. Although this is a retrospective study, its findings describe the pattern and situation of general surgical practice in low income countries like ours.

\section{Conclusions}

This study showed majority of the surgical patients are managed as an out-patient in the surgical emergency department and emergency surgeries account for most of the surgeries done in our hospital. The most commonly performed major emergency procedure is simple and complicated appendicitis. Significant number elective operations are cancelled for various reasons.

We suggest that audit should be carried out on regular basis in all hospitals since it provides insight and feedback to the hospital's and surgeon's performance. It serves as a tool to effectively improve the overall patient care in surgical emergencies [15].

\section{Limitation of the study}

The limitation of this study is the fact that is a retrospective and relies on records/registries which are prone to be incomplete.

\footnotetext{
Abbreviations

ZMH: Zewditu Memorial Hospital; OR: operation room; ESOPD: emergency surgical outpatient department; SRS: surgical referral clinic; LMIC: low and middle income countries; Post-op: post-operative; AAU: Addis Ababa university; CHS: College of Health Sciences; SOM: School of Medicine; HAP: hospital acquired pneumonia.
}

\section{Acknowledgements}

We would like to thank the management as well as staffs, residents, colleagues of Zewditu Memorial hospital for their support during collection of the required information.

\section{Authors' contributions}

HWG and GT are consultant surgeons and assistant professors of surgery at department and participated in most of the surgeries. Both authors read and approved the final manuscript.
Funding

No funding was used in the writing of the manuscript.

Availability of data and materials

There are no additional data and materials beyond those mentioned within the manuscript.

\section{Ethics approval and consent to participate}

Approval to do the review were obtained from department of surgery. Consent to participate is not required for chart review.

\section{Consent to publish}

Not applicable.

\section{Competing interests}

The author declares that they have no competing interests.

Received: 21 Auqust 2019 Accepted: 4 October 2019

Published online: 22 October 2019

\section{References}

1. Faizan S, Ghazanfar M. Surgical audit and research. J Univers Surg. 2017;5(3):16.

2. Rose J, Weiser TG, Hider P, Wilson L, Gruen RL, Bickler SW. Estimated need for surgery worldwide based on prevalence of diseases : a modelling strategy for the WHO Global Health Estimate. Lancet Glob Health. 2010;3(Gbd):S13-20. https://doi.org/10.1016/S2214-109X(15)70087-2.

3. Nepogodiev D, Martin J, Biccard B, Makupe A, Bhangu A, Ademuyiwa A, et al. Global burden of postoperative death. Lancet. 2019;393(10170):401.

4. Campbell WB, Lee EJK, Van de Sijpe K, Gooding J, Cooper MJ. A 25-year study of emergency surgical admissions. Ann R Coll Surg Engl. 2002;84(4):273-7.

5. Ibrahim NA, Oludara MA, Ajani A, Mustafa I, Balogun R, Idowu O, et al. Non-trauma surgical emergencies in adults: spectrum, challenges and outcome of care. Ann Med Surg. 2015;4(4):325-30.

6. Ps A, Oboirien M, State O, Adedayo O, Abraham D, Adem A. AA, et al. Surgical emergencies in a Nigerian Teaching Hospital.pdf. Niger postgraduate Med J. 2003;10(3):140-3. http://www.bjs.co.uk.

7. Khalid S, Bhatti AA, Burhanulhuq. Audit of surgical emergency at lahore general hospital. J Ayub Med Coll Abbottabad. 2015;27(1):74-7.

8. Dhingra J, Arora G, Souza PD. A study of disease pattern in patients presenting in the emergency department of a tertiary hospital catering to industrial workers. IOSR J Dent Med Sci. 2014;13(5):71-5.

9. Mccord C, Ozgediz D, Beard JH, Debas HT. General surgical emergencies, essential surgery: disease control priorities, vol. 1. 3rd ed. Washington, DC: World Bank; 2016. p. 1-30.

10. Abraham D. Pattern and clinical presentation of acute appendicitis in adults in Zewditu Memorial Hospital. Ethiop J Health Sci. 2003;13(2):117-23.

11. Adem AAA. Pattern of surgical admissions to Tikur Anbessa. EMJ. 1997:353:74-7.

12. Harrison E. Quality and outcomes in global cancer surgery: Protocol for a multicentre, international, prospective cohort study (GlobalSurg 3). BMJ Open. 2019;9(5):e026646.

13. Samuel JC, Qureshi JS, Mulima G, Shores CG, Cairns BA, Charles AG. An Observational Study of the Etiology, clinical presentation and outcomes associated with peritonitis in Lilongwe, Malawi. World J Emerg Surg. 2011;6(1):37.

14. Hunchak C, Teklu S, Meshkat N, Meaney C, Ritchie LP. Patterns and predictors of early mortality among emergency department patients in Addis Ababa, Ethiopia. BMC Res Notes. 2015;8:605. https://doi.org/10.1186/ s13104-015-1592-z

15. Rugwizangoga MN. Outcome of emergency abdominal surgery at Kigali University Teaching Hospital: a review of 229 cases. East Centre Afr J surg Outcome. 2013;18(1):31-9.

16. Bhangu A, Ademuyiwa AO, Aguilera ML, Alexander P, Al-Saqqa SW, BordaLuque $G$, et al. Surgical site infection after gastrointestinal surgery in highincome, middle-income, and low-income countries: a prospective, international, multicentre cohort study. Lancet Infect Dis. 2018;18(5):516-25. 
17. Chukuezi AB, Nwosu JN. Mortality pattern in the surgical wards: a five year review at Federal Medical Centre, Owerri. Nigeria. Int J Surg. 2010;8(5):381-3. https://doi.org/10.1016/j.ijsu.2010.05.010.

18. World Health Organisation. Surgical care systems strengthening, developing national surgical, obstetric and anaesthesia plans. Geneva: WHO; 2017.

19. Chalya PL, Gilyoma JM, Mabula JB, Simbila S, Ngayomela IH. Incidence, causes and pattern of cancellation of Elective surgical operations in a
University Teaching Hospital in the Lake Zone. Tanzania. Afr Health Sci. 2011;11(3):1-10.

\section{Publisher's Note}

Springer Nature remains neutral with regard to jurisdictional claims in published maps and institutional affiliations.
Ready to submit your research? Choose BMC and benefit from:

- fast, convenient online submission

- thorough peer review by experienced researchers in your field

- rapid publication on acceptance

- support for research data, including large and complex data types

- gold Open Access which fosters wider collaboration and increased citations

- maximum visibility for your research: over $100 \mathrm{M}$ website views per year

At BMC, research is always in progress.

Learn more biomedcentral.com/submissions 